\title{
Flora da Bahia: Cunoniaceae
}

\author{
Pâmela Novais de Oliveira ${ }^{1, a}$, Lucas Cardoso Marinho ${ }^{1,2^{*}}$, Luciano Paganucci de Queiroz ${ }^{1, b}$ \& Ana Maria \\ Giulietti $^{1,3, c}$
}

${ }^{1}$ Programa de Pós-Graduação em Botânica, Departamento de Ciências Biológicas, Universidade Estadual de Feira de Santana, Bahia, Brasil.

${ }^{2}$ Departamento de Biologia, Centro de Ciências Biológicas e da Saúde, Universidade Federal do Maranhão, São Luís, Maranhão, Brasil.

${ }^{3}$ Herbarium, Royal Botanic Gardens, Kew, Reino Unido.

\begin{abstract}
Resumo - É apresentado o levantamento florístico de Cunoniaceae da Bahia, Brasil. Foram encontrados dois gêneros e quatro espécies: Lamanonia speciosa, restrita ao Planalto de Conquista, no sudeste do estado; L. ternata, amplamente distribuída na Chapada Diamantina e na Mata Atlântica do sul da Bahia; Weinmannia humilis, registrada aqui pela primeira vez na Bahia, ocorrendo apenas em florestas montanas do sul do estado; e W. paulliniifolia, restrita à Chapada Diamatina. É apresentada uma chave de identificação para gêneros e espécies, além de descrições, ilustrações e comentários gerais sobre a distribuição e afinidades morfológicas das espécies.
\end{abstract}

Palavras-chave adicionais: Brasil, florística, Lamanonia, taxonomia, Weinmannia.

\begin{abstract}
Flora of Bahia: Cunoniaceae) - We present a floristic survey of the Cunoniaceae of the state of Bahia, Brazil. Four species in two genera were found: Lamanonia speciosa, restricted to the Conquista Plateau, in the southeast of the state; L. ternata, widely distributed in the Chapada Diamantina and Atlantic Forest of southern Bahia; Weinmannia humilis, recorded here for the first time in Bahia, only in the montane forests of the south of the state; and W. paulliniifolia, restricted to the Chapada Diamatina. A taxonomic key, descriptions, illustrations, and general notes on species distribution and morphological affinities are provided.
\end{abstract}

Additional key words: Brazil, floristics, Lamanonia, taxonomy, Weinmannia.

\section{CUNONIACEAE}

Árvores ou arbustos. Estípulas geralmente conspícuas e interpeciolares, decíduas ou persistentes. Folhas opostas ou verticiladas, compostas, digitadas ou pinadas, raramente unifolioladas; folíolos com margens geralmente crenadas, serreadas ou denteadas. Inflorescências terminais ou axilares, raramente caulifloras, paniculadas, tirsoides ou cimosas, raramente flores isoladas. Flores actinomorfas, diclamídeas ou monoclamídeas, uni- ou bissexuadas; sépalas (3)4 ou 5(-10), livres ou unidas na base; pétalas em número igual ao das sépalas, raramente ausentes ou mais numerosas, livres ou raramente unidas na base; androceu geralmente diplostêmone, raramente polistêmone, filetes maiores do que o perianto, anteras bitecas, rimosas; disco nectarífero geralmente presente; ovário súpero, raramente ínfero, sincárpico, 2-5-locular raramente 1- ou 4-14-locular, óvulos (1)2 a muitos por lóculo, placentação axilar ou pêndula, estiletes 2, livres entre si. Frutos indeiscentes ou deiscentes e então cápsulas septicidas ou folículos. Sementes numerosas, aladas ou não, indumentadas ou glabras.

\footnotetext{
*Autor para correspondência: 1cmarinho1@gmail.com; apam_lhug@hotmail.com; bluciano.paganucci@gmail.com; cagiuliettiharley@gmail.com;

Editor responsável: Alessandro Rapini

Submetido: 19 ago. 2019; aceito: 6 dez. 2019

Publicação eletrônica: 12 dez. 2019; versão final: 18 dez. 2019
}

Cunoniaceae possui cerca de 300 espécies distribuídas em 27 (Bradford et al. 2004) ou 29 gêneros (Stevens 2001). Está incluída em Oxalidales (Bradford \& Barnes 2001; APG IV 2016) com mais seis famílias, das quais Brunelliaceae, Connaraceae, Oxalidaceae e Elaeocarpaceae também ocorrem nas Américas. Cunoniaceae é grupo irmão do clado composto por Brunelliaceae, Cephalotaceae e Elaeocarpaceae (Stevens 2001) compartilhando as folhas (ou folíolos) com margens denteadas, estipuladas, e flores com disco nectarífero. Porém, enquanto Cunoniaceae tem como sinapormorfia a presença de um só par de estípulas interpeciolares, as duas outras famílias possuem estípulas laterais (Bradford et al. 2004). Uma exceção é Lamanonia Vell. que apresenta dois pares de estípulas laterais e livres por nó (Hopkins 2018). A família é predominantemente do hemisfério sul, ocorrendo nas Américas, desde a Guatemala até o sul da América do Sul, extremo sul da África, incluindo Madagascar, Oceania e ilhas dos oceanos Índico e Pacífico (Stevens 2001; Bradford et al. 2004). Os fósseis de Cunoniaceae estão presentes especialmente na Austrália, Nova Zelândia e Antártica e constam principalmente de impressões de folhas, lenho e grãos de pólen, e sugerem que a diversificação da família tenha ocorrido no Cretáceo Médio e Superior (Poole et al. 2000; Bradford et al. 2004).

No Brasil, ocorrem os gêneros Lamanonia e Weinmannia L., cada um deles com seis espécies e com representantes em todas as regiões do país 
(Santos-Silva et al. 2019). Para o Pico das Almas, na Chapada Diamantina, foram registradas Lamanonia ternata Vell. e Weinmannia paulliniifolia Pohl (Zappi \& Taylor 1995). Neste trabalho, os dois gêneros foram confirmados para a Bahia, cada um deles com duas espécies, sendo $W$. humilis Engl. registrada pela primeira vez para o estado.

\section{Chave para gêneros e espécies}

1. Folhas digitadas com 3 ou 5 folíolos; corola ausente; estames 20-60; cápsulas pubérulas a seríceas; sementes glabras e aladas .. 1. Lamanonia

2. Estípulas semicordadas, coriáceas, persistentes; folíolos coriáceos, com base aguda a arredondada 1.1. L. speciosa

2'. Estípulas semifalcadas ou raramente orbiculares, cartáceas, decíduas ou raramente persistentes; folíolos cartáceos ou subcoriáceos, com base atenuada

1.2. L. ternata

1'. Folhas pinadas; corola presente; estames 8-10; cápsulas glabras; sementes pilosas e não-aladas

2. Weinmannia

3. Ramos jovens e maduros tomentosos; folíolos laterais em 6-9 pares 2.1. W. humilis

3'. Ramos jovens tomentosos, glabrescentes quando maduros; folíolos laterais em 3 ou 4 pares

2.2. W. paulliniifolia

\section{Lamanonia Vell.}

Árvores ou arbustos. Estípulas livres, dois pares por nó, falcadas, semicordadas ou orbiculares, decíduas ou persistentes. Folhas oposto-cruzadas, digitadas; folíolos 3 ou 5, sésseis ou subsésseis, margens serreadas, domácias na face abaxial. Inflorescências racemos axilares (às vezes referidos como pseudorracemosas), multifloras. Flores monoclamídeas, bissexuadas; sépalas 6 , brancas, unidas na base; pétalas ausentes; estames numerosos, 20-60, livres, heterodínamos; disco nectarífero adnato ao ovário, anelado; ovário súpero, ovoide a oblongo, bilocular, velutino a tomentoso, estiletes 2, reflexos ou patentes, glabros, estigmas capitados. Cápsulas lenhosas, pubérulas a seríceas, bivalvares. Sementes numerosas, dorsalmente aladas, glabras.

Lamamonia inclui seis espécies neotropicais distribuídas na Argentina, Brasil e Paraguai, todas com ocorrência no Brasil (Zickel \& Leitão-Filho 1993; Santos-Silva et al. 2017; Hopkins 2018). Na Bahia, são registradas duas espécies: $L$. speciosa, restrita ao Planalto de Conquista, no sudeste do estado, e $L$. ternata, amplamente distribuída na Chapada Diamantina e na Mata Atlântica do sul do estado.

1.1. Lamanonia speciosa (Cambess.) L.B.Sm., J. Wash. Acad. Sci. 48: 283. 1958.

Figuras $1 \mathrm{~A}-\mathrm{C}$ e 3 .

Árvores ou arbustos 2-6 m alt.; ramos jovens pilosos. Estípulas $7-20 \times 5-15 \mathrm{~mm}$, semicordadas, coriáceas, persistentes, glabras, pubérulas ou tomentosas, margens inteiras. Folhas 3(5)-folioladas; pecíolo 1-2 cm compr., glabros ou pubescentes na base da inserção dos folíolos; folíolos subsésseis, coriáceos, oblongo-elípticos, ápice agudo, base arredondada, folíolo terminal 4-7,5 × 1,5-3,5 cm, folíolos laterais 2$4,5 \times 1-2 \mathrm{~cm}$, face adaxial glabra, face abaxial pubérula com nervura central pubérula a pubescente. Inflorescências 7-13 cm compr.; pedúnculo 5-6 cm compr., piloso; pedicelos 3-5 mm compr., tomentosos. Sépalas ca. $5 \mathrm{~mm}$ compr., lanceoladas, densamente seríceas; estames ca. 30, 6-7 mm compr.; ovário ca. 5 $\times 2 \mathrm{~mm}$, oblongo a ovoide, constrito na porção basal, velutino, estiletes ca. $3 \mathrm{~mm}$ compr., reflexos. Cápsulas $1,2-1,5 \times 0,4-0,5 \mathrm{~cm}$, ovoides a elipsoides, hirsutas. Sementes ca. $6 \times 2 \mathrm{~mm}$, elípticas.

Lamanonia speciosa era referida exclusivamente para Minas Gerais (Santos-Silva et al. 2019), sendo aqui registrada pela primeria vez na Bahia, em duas localidades no Planalto de Conquista, sudeste do estado. G7, H6: floresta estacional decidual. Floresce e frutifica de janeiro a agosto.

Material selecionado - Encruzilhada, estrada Divisa Alegre/Divisópolis, $15^{\circ} 44^{\prime} \mathrm{S}, 41^{\circ} 09^{\prime} \mathrm{W}, 9$ ago. 1984 (fr.), M.M. Santos et al. 157 (CEPEC, HUEFS, IPA); Vitória da Conquista, $\mathrm{Km} 20$ da rodovia Conquista/Barra do Choça, 14²51'58"S, 4050'22"W, 7 jan. 1973 (fl., fr.), T.S. Santos 2583 (CEPEC, IPA).

Material adicional examinado - BRAZIL. MINAS GERAIS: Santana do Riacho, Km 114 ao longo da rodovia Belo Horizonte/Conceição do Mato Dentro, 28 fev. 1981 (fr.), S. Mayo et al. CFSC 7031 (HUEFS).

Os espécimes estudados foram inicialmente identificados como Lamanonia grandistipularis (Taub.) Taub. utilizando a revisão do gênero (Zickel \& Leitão-Filho 1993) e a Flora da Serra do Cipó (Pirani \& Castro 2011), onde está incluída uma ilustração completa da espécie. Lamanonia grandistipularis foi caracterizada especialmente pela presença de folíolos coriáceos e estípulas semicordadas, persistentes tanto na fase vegetativa como na floração e frutificação, sendo referida para os estados da Bahia, Minas Gerais, Espírito Santo e Rio de Janeiro (Zickel \& Leitão-Filho 1993). Hopkins (2018) não encontrou diferenças morfológicas entre os materiais-tipo de Belangera speciosa Cambess., publicada em 1829, e $B$. grandistipularis Taub., publicada em 1890, que justificasse o reconhecimento de duas espécies e considerou Lamanonia speciosa o nome correto da espécie. Esse posicionamento é aceito na Flora do Brasil 2020 (Santos-Silva et al. 2019) e adotado aqui.

1.2. Lamanonia ternata Vell., Fl. Flumin. 228. 1829; (Icones) vol. 5: tab. 104. 1831

Figuras 1D-G, 2 e 3.

Árvores 2-22 m alt.; ramos jovens pilosos. Estípulas 4-15 × 2-10 mm, semifalcadas, raramente orbiculares, cartáceas, decíduas, raramente persistentes, esparsamente pubescentes, margens inteiras. Folhas 3ou 5-folioladas; pecíolo 3-15 cm compr., pilosos ou 


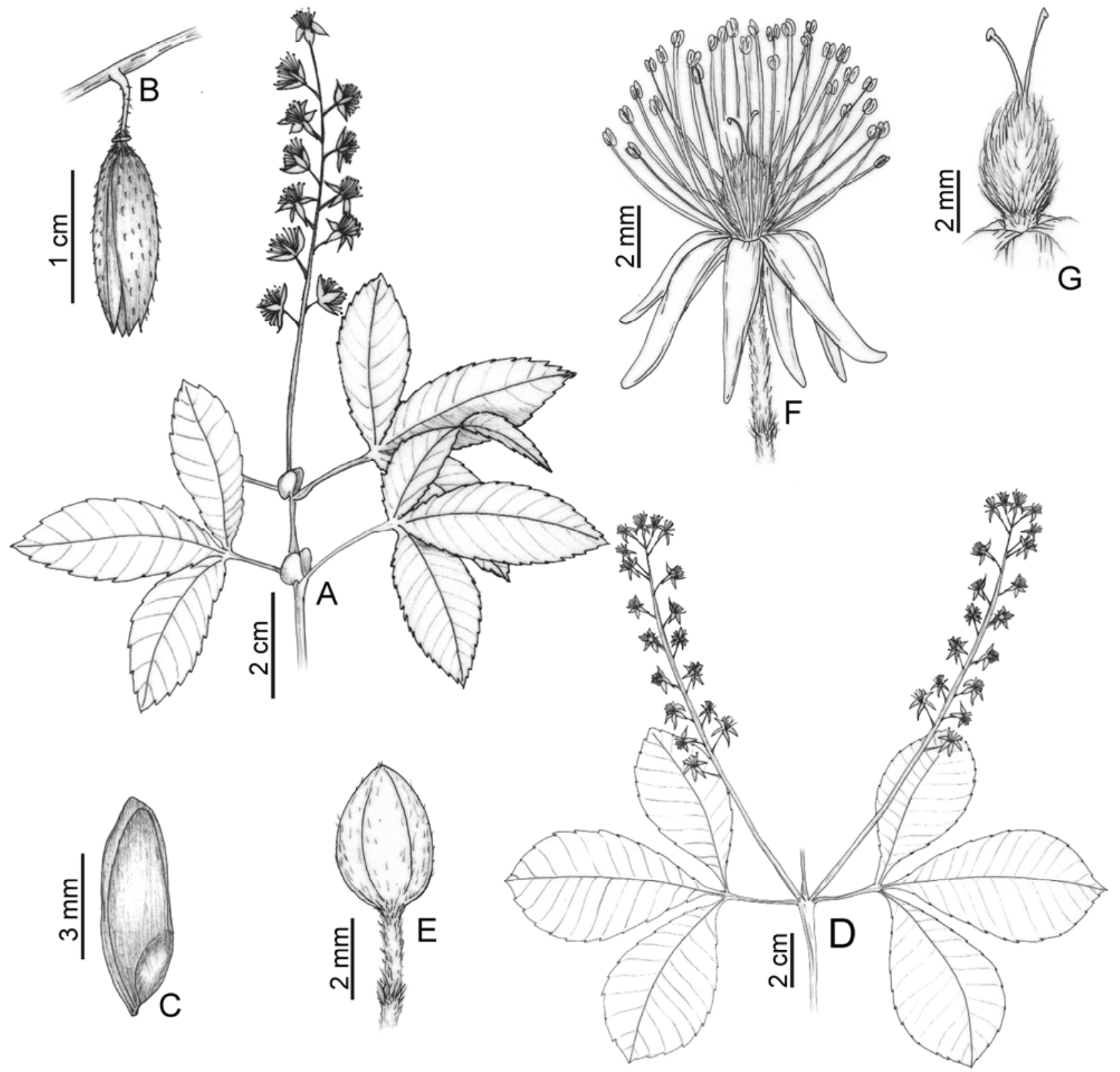

Figura 1. A-C. Lamanonia speciosa: A- ramo florífero; B- fruto; C- semente alada. D-G. L. ternata: D- ramo florífero; E- botão floral; F- flor aberta; G- detalhe do pistilo (A- Santos 2583; B-C- Santos 157; D- Amorim 4830; E-G- Harley 58287). Ilustrado por Karena Pimenta e Lucas Marinho.

tomentosos; folíolos subsésseis, cartáceos ou subcoriáceos, oblongo-elípticos a oboval-oblongos, ápice agudo ou acuminado, base atenuada, folíolo terminal 5,5-32 × 2,5-6,6 cm, folíolos laterais 4-22 $\times$ 1,5-5,5 compr., face adaxial glabra exceto pela nervura central pubérula, face abaxial pubérula a tomentosa. Inflorescências 11-17,5 cm compr.; pedúnculo 4-9 $\mathrm{cm}$ compr., piloso; pedicelos 5-10 $\mathrm{mm}$ compr., densamente pilosos, com um adensamento de tricomas na porção proximal. Sépalas 3-5 $\mathrm{mm}$ compr., lanceoladas, face externa esparsamente pubérula, face interna densamente serícea; estames 30-35, 5-6 mm compr.; ovário 3-5 × 1,5-3 mm, oblongo, constrito na porção basal, seríceo-velutino, estiletes ca. 2,5 mm compr., eretos. Cápsulas 1,2-1,5 $\times 0,5-1 \mathrm{~cm}$, oblongas, seríceas. Sementes $4-5 \times 1,5$ $\mathrm{mm}$, elípticas.

Seguindo a circunscrição de Zickel \& Leitão-Filho (1993) e Pirani \& Castro (2011), Lamanonia ternata não é endêmica do Brasil, ocorrendo também na Argentina e Paraguai. Diferentemente, Santos-Silva et al. $(2017,2019)$ atribuem à espécie o status de endêmica do Brasil, ocorrendo em todos os estados das Regiões Centro-Oeste, incluindo o Distrito Federal, Sudeste e Sul, além da Bahia e Pernambuco na Região Nordeste (Santos-Silva et al. 2019). D7, E6, E7, E8, F5, F6, F8, G8, H8, H9, I8, J8: floresta ombrófila densa, mata de altitude, floresta estacional semidecidual e mata ciliar. Floresce entre dezembro e maio, frutificando entre fevereiro e setembro. 

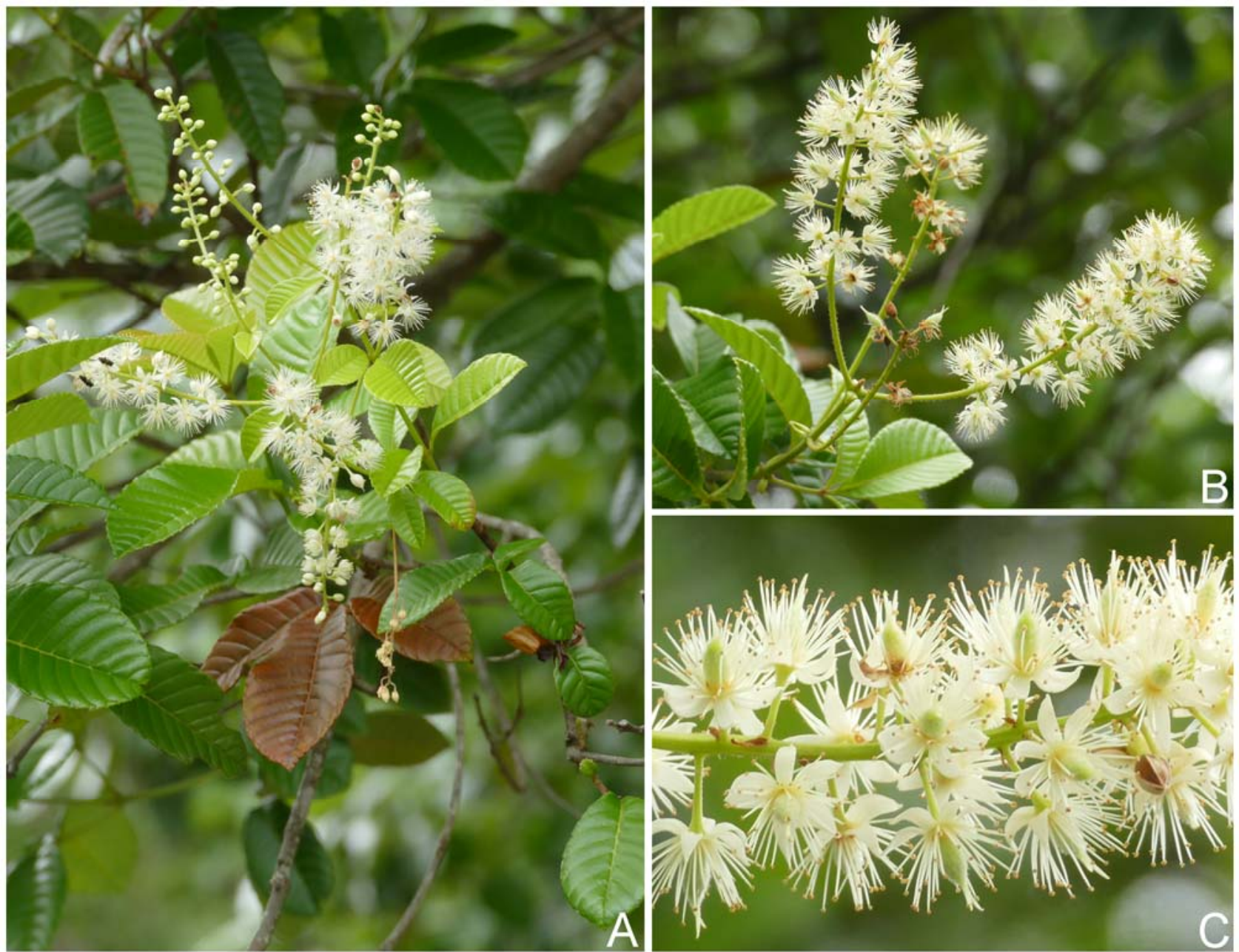

Figura 2. Lamanonia ternata: A- ramo florífero; B- inflorescência; C- detalhe da inflorescência (Fotos: R.M. Harley, do espécime Harley 58287).

Material selecionado - Abaíra, distrito de Catolés, $13^{\circ} 16^{\prime} \mathrm{S}$, 4153'W, 14 maio 1992 (bot., fl.), W. Ganev 261 (HUEFS); Almadina, rodovia Almadina/Ibitupã, 1442'19"S, 39³8'14"W, 15 jun. 1998 (fl.), J.G. Jardim et al. 1222 (CEPEC, NY); Arataca, Serra das Lontras, $15^{\circ} 10^{\prime} 25^{\prime \prime} \mathrm{S}, 39^{\circ} 20^{\prime} 30^{\prime \prime} \mathrm{W}, 12$ fev. 2005 (fr.), J.G. Jardim et al. 4406 (CEPEC, HUEFS); Barro Preto, Serra da Pedra

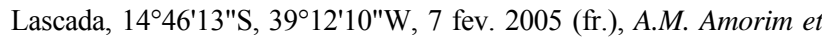
al. 4830 (CEPEC, NY, SPF); Belmonte, fazenda Brejinho, 1551'57"S, 38 52'58"W, 27 abr. 1972 (fl.), M.T. Monteiro 23663 (HST, HUEFS); Camacan, RPPN Serra Bonita, 15²3'30"S, 39³3'55"W, 25 mar. 2007 (est.), A.M. Amorim et al. 6963 (CEPEC); Castro Alves, Serra da Jiboia, 1351'S, 39²8'W, 18 jun. 1993 (est.), L.P. Queiroz et al. 3236 (HUEFS); Itaberaba, Serra do Orobó, 12²4'53"S, 40³2'15"W, 19 jan. 2006 (fl.), L.P. Queiroz et al. 12092 (HUEFS); Ituberá, Reserva Ecológica Michelin, 1343'56"S, 3908'57"W, ago. 2010 (est.), R.B. Oliveira et al. 12 (ALCB); Jacobina, estrada para Pingadeira, $11^{\circ} 09^{\prime} 02^{\prime \prime S}, 40^{\circ} 31^{\prime} 26^{\prime \prime} \mathrm{W}, 26 \mathrm{abr}$. 2019 (fl.), R.M. Harley et al. 58287 (HUEFS); Lençóis, Morro da Chapadinha, 12²7'35"S, 4126'25"W, 29 dez. 1994 (bot.), M.L. Guedes et al. PCD1486 (ALCB, CEPEC, HUEFS); Miguel Calmon, Sete Passagens, $11^{\circ} 20^{\prime} \mathrm{S}, 40^{\circ} 31^{\prime} \mathrm{W}, 15$ jun. 2006 (est.), R.M. Valadão et al. 135 (ALCB); Mucugê, PARNA Chapada Diamantina, $12^{\circ} 43^{\prime} \mathrm{S}, 41^{\circ} 30^{\prime} \mathrm{W}, 2$ fev. 2009 (fl.), D. Cardoso et al. 2400 (HUEFS); Piatã, encosta da Serra do Barbado, $13^{\circ} 17^{\prime} \mathrm{S}$,

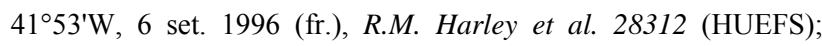

Prado, Parque Nacional do Descobrimento, $17^{\circ} 11^{\prime}$ S, $39^{\circ} 20^{\prime} \mathrm{W}, 4$ nov. 2009 (est.), F.B. Matos et al. 1928 (CEPEC); Rio de Contas, Serra das Almas, 1330'43"S, 41 57'45"W, jan. 2006 (bot., fl.), F.H.F. Nascimento 527 (HUEFS); Rui Barbosa, Serra do Orobó, $12^{\circ} 18^{\prime} 47^{\prime \prime S}, 40^{\circ} 29^{\prime} 01^{\prime \prime W}, 18$ dez. 2004 (fl.), L.P. Queiroz et al. 9918 (HUEFS); Santa Terezinha, Serra da Jiboia, 1251'10"S, $39^{\circ} 28^{\prime} 32^{\prime \prime W}, 27$ set. 2000 (est.), L.P. Queiroz et al. 6371 (HUEFS).

Lamanonia ternata caracteriza-se pelas estípulas semifalcadas, que podem ser desenvolvidas, particularmente em ramos novos e rebrotos, e pelos folíolos cartáceos. Diferencia-se de L. speciosa pela forma da estípula (semifalcada vs. semicordada em $L$. speciosa) e folíolos com base atenuada (vs. base aguda a arredondada). Além disso, apresenta pedicelos maiores (5-10 $\mathrm{mm}$ vs. 3-5 mm compr.), cápsulas oblongas (vs. ovoides a elipsoides) e sementes menores (4-5 $\mathrm{mm}$ vs ca. $6 \mathrm{~mm}$ compr.). Lamanonia denticulata (Moric.) Kuntze foi a única espécie descrita com material-tipo coletado na Bahia (Blanchet 3253), em localidade incerta nos arredores de Jacobina (Hopkins 2018). Zickel \& Leitão-Filho (1993), no entanto, consideraram L. denticulata sinônimo de $L$. ternata. Ilustrações recentes de $L$. ternata podem ser vistas em Pirani \& Castro (2011: 43) e Santos-Silva et al. (2017: 108). 


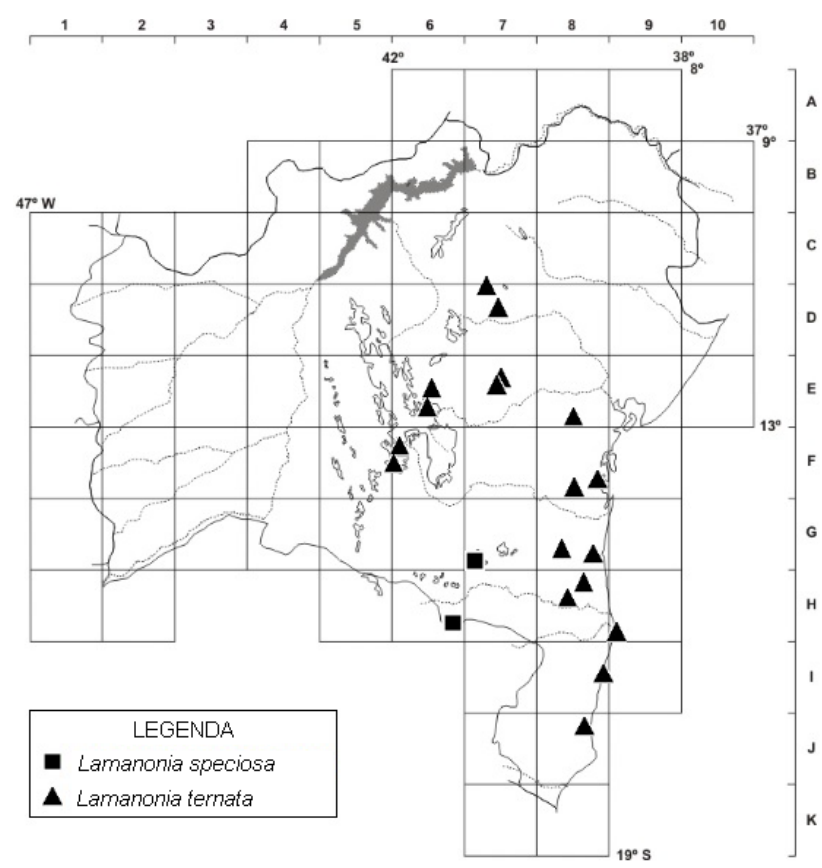

Figura 3. Distribuição de Lamanonia speciosa e L. ternata no estado da Bahia.

Alguns espécimes da Bahia, a exemplo de Harley 58287 e Queiroz 12092, apresentam uma leve constrição, com menor concentração de tricomas, na porção basal do ovário (Figura $1 \mathrm{G}$ ). Esse caráter não é mencionado para L. ternata em Pirani \& Castro (2011) e Santos-Silva et al. (2017), mas é ilustrado em L. speciosa (como "L. grandistipularis") em Pirani \& Castro (2011). Um adensamento de tricomas na porção proximal do pedicelo, similar a uma articulação e possivelmente proveniente de uma redução da inflorescência, também pode ser observado em espécimes de L. ternata (Figuras 1E e 2C).

Pirani \& Castro (2011) comentaram que Lamanonia ternata pode incluir grandes árvores florestais, enquanto L. grandistipularis $(=L$. speciosa) abrange arvoretas delgadas do campo rupestre. Na Bahia, apesar de alguns espécimes de L. ternata serem árvores de até $22 \mathrm{~m}$ de altura em áreas associadas à Mata Atlântica, a maioria dos espécimes examinados, da região da Chapada Diamantina, são arbustos de até $3 \mathrm{~m}$ de altura ou arvoretas de 6-8 $\mathrm{m}$ de altura, ocorrendo em matas ciliares. Essa variação é mantida possivelmente devido à disjunção entre a Mata Atlântica e a Chapada Diamantina. Algumas espécies, como Bonnetia stricta (Nees) Nees \& Mart. (Bonnetiaceae; Costa et al. 2010) e Laplacea fruticosa (Schrad.) Kobuski (Theaceae; Marinho et al. 2015), também se apresentam como árvores na Mata Atlântica, mas possuem um porte menor na Chapada Diamantina.

\section{Weinmannia $\mathrm{L}$.}

Árvores ou arbustos. Estípulas livres, falcadas a circulares, decíduas ou persistentes. Folhas opostocruzadas, menos frequentemente verticiladas, pinadas, com segmentos interfoliolares da raque alados ou não, ou unifolioladas; folíolos peciolulados ou subsésseis, margens geralmente denteadas, raro serreadas; pecíolo alados ou não. Inflorescências tirsos ou racemos terminais ou axilares (às vezes referidas como pseudorracemosas), multifloras. Flores diclamídeas, bissexuadas; sépalas geralmente 5 , unidas na base; pétalas 5 , iguais entre si, persistentes ou decíduas; estames 10 , livres, heterodínamos; disco nectarífero adnato ao ovário, anelado ou segmentado; ovário súpero, elíptico, ápice bífido, bilocular, glabro, estiletes ascendentes, divergentes, estigma levemente capitado. Cápsulas coriáceas, glabras, bivalvares. Sementes numerosas, pilosas ou com tricomas esparsos, não aladas.

Weinmannia inclui cerca de 160 espécies, estendendo-se por toda a área de distribuição de Cunoniaceae (Stevens 2001; Bradford et al. 2004). Análises filogenéticas com dados morfológicos sugerem que as sementes com tricomas sejam uma sinapomorfia do gênero (Bradford 1998). As cinco seções propostas em Weinmannia são monofiléticas, mas dados moleculares não resolvem a posição do gênero em relação a Cunonia L. (Bradford \& Barnes 2001; Bradford et al. 2004). Bernardi (1961) revisou a taxonomia de Weinmannia sect. Weinmannia, a única seção que inclui espécies americanas, e reconheceu 50 espécies e sete séries. Na região neotropical, ocorrem 77 espécies, com maior riqueza na Amazônia; Colômbia e Peru são os países com maior número (23) de espécies (Gutiérrez 1993; Fuentes \& Rogers 2007). No Brasil, são registradas seis espécies, cinco delas mais a leste, nas Regiões Sudeste e Sul, além da Bahia; apenas $W$. fagaroides Kunth, registrada no estado do Amazonas (SantosSilva et al. 2019), não havia sido referida para o Brasil por Bernardi (1961). Na Bahia, ocorrem W. paulliniifolia e $W$. humilis, esta última registrada pela primeira vez para o estado.

2.1. Weinmannia humilis Engl., Linnaea 36: 620. 1870

Figuras $4 \mathrm{~A}-\mathrm{G}$ e 6.

Árvores até $6 \mathrm{~m}$ alt.; ramos jovens e maduros tomentosos. Estípulas $2-3 \mathrm{~mm}$ compr., circulares. Folhas 3-5,5(-7,5) cm compr., imparipinadas, subsésseis ou com pecíolo 3-4 $\mathrm{mm}$ compr., estreitamente alado, tomentoso ou com tricomas esparsos, segmentos interfoliolares da raque alados, alas rômbicas, glabras; folíolos 13-19, sésseis, cartáceos, oboval-elípticos a oblongo-elípticos, ápice obtuso, agudo no folíolo terminal, base arredondada, margens serreadas no $1 / 3-2 / 3$ distal, pouco revolutas, faces adaxial e abaxial glabras, nervura central glabra, folíolo terminal $0,6-1,1(-3) \times 0,3-$ $0,5(-1) \mathrm{cm}$, folíolos laterais $0,5-0,75(-2,5) \times 0,4$ $0,5(-1,3) \mathrm{cm}$. Inflorescências $4,6-7,3 \mathrm{~cm}$ compr., terminais, 2 por ápice de ramo; pedúnculo $1-1,5 \mathrm{~cm}$ compr., tomentoso; pedicelos 1,5-4 mm compr., pilosos. 


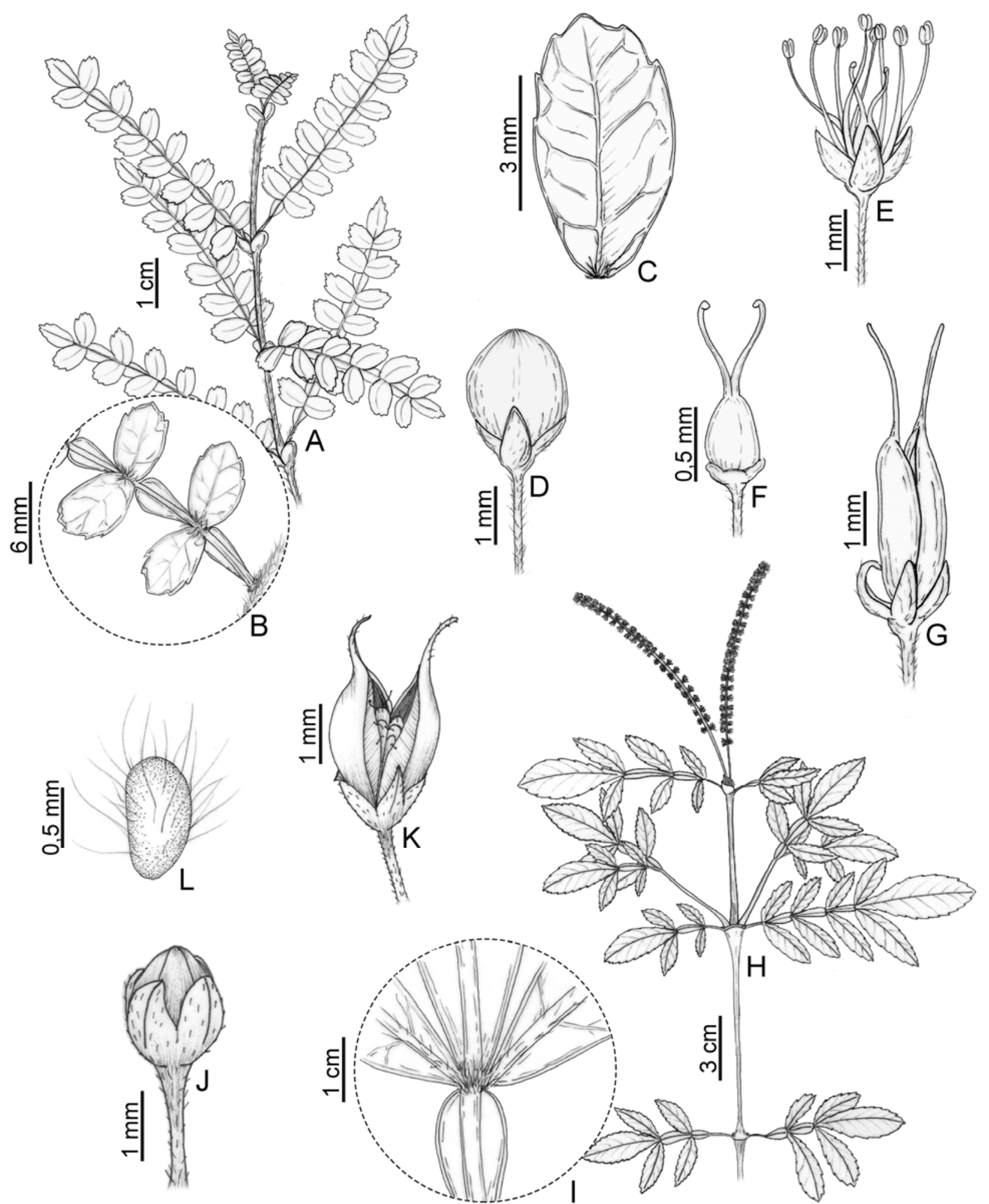

Figura 4. A-G. Weinmannia humilis: A- ramo estéril; B- detalhe do pecíolo e raque, mostrando o pecíolo e os segmentos interfoliolares da raque alados; C- folíolo lateral (face abaxial); D- botão floral; E- flor, pétalas removidas; F- pistilo; G- fruto. H-L. W. paulliniifolia: H- ramo florífero; I- detalhe da raque foliar, mostrando parte dos segmentos interfoliolares alados; J- botão floral; K- fruto; L- semente (A-C- Amorim 5789; D-F- Barbosa 953; G- Sohn 36; H-J- Hurbath 129; K-L- Juchum 95). Ilustrado por Karena Pimenta e Lucas Marinho.

Sépalas $4,0,7-1 \times$ ca. $0,7 \mathrm{~mm}$ compr., ovais, ápice agudo, base truncada, pubérulas; pétalas 4 , ca. $1,2 \times 1$ $\mathrm{mm}$, brancas, ovais a oblongas, ápice obtuso, base truncada, côncavas, glabras, precocemente caducas; estames 10, 2-2,5 mm compr., filetes glabros; ovário 0,5-
$0,7 \times$ ca. $0,6 \mathrm{~mm}$, oblongo-ovoide, glabro, estiletes $1-1,2$ mm compr. Cápsulas 3,8-4 × 1,1-1,5 mm, oblongas. Sementes ca. $0,7 \times 0,5 \mathrm{~mm}$, ovoides a reniformes.

Weinmannia humilis é endêmica do Brasil, ocorrendo em todos os estados das Regiões Sudeste e 

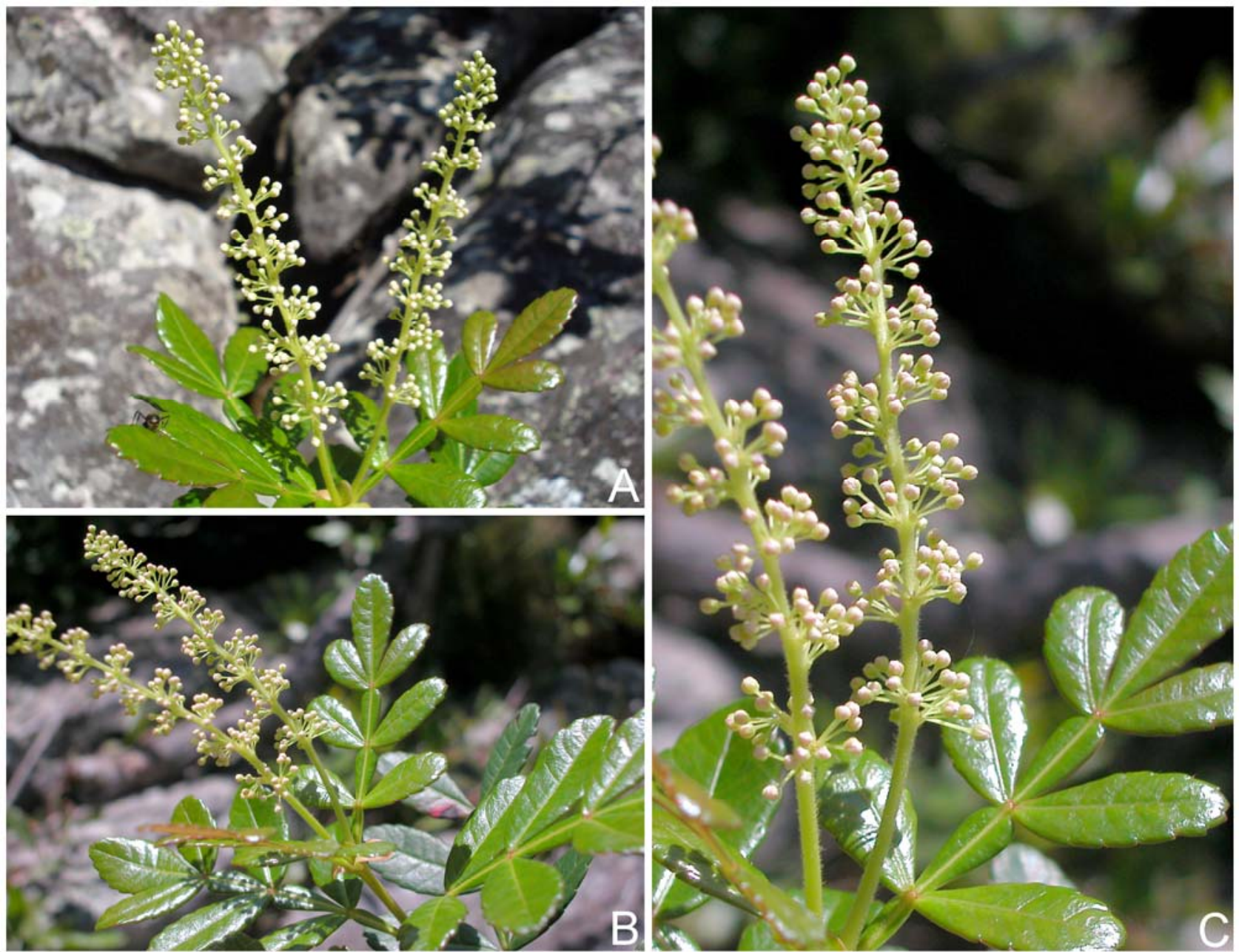

Figura 5. Weinmannia paulliniifolia: A-B- ramo florífero; C- detalhe da inflorescência em botões (Fotos: R.M. Harley, do espécime Harley 55895).

Sul (Santos-Silva et al. 2019). Na Bahia, é conhecida de apenas uma localidade, no sul da Bahia. H8: floresta montana ombrófila densa. Não foi possível inferir a fenologia com base nos espécimes da Bahia; de acordo com o material adicional examinado, a espécie floresce e frutifica em fevereiro.

Material selecionado - Arataca, Serra do Peito de Moça, $15^{\circ} 10^{\prime} 25^{\prime \prime S}, 39^{\circ} 20^{\prime} 30^{\prime \prime W}, 15$ abr. 2006 (est.), A.M. Amorim et al. 5789 (CEPEC, HUEFS, RB, SPF).

Material adicional examinado - BRASIL. PARANÁ: Piraquara, Morro do Canal, 15 fev. 2004 (fl.), E. Barbosa 953 (HUEFS, MBM). SANTA CATARINA: Urupema, $5 \mathrm{~km}$ de Urupema para Rio Ruffino, 13 fev. 1981 (fr.), S. Sohn \& J.M. Campos 36 (FLOR, HUEFS).

Os dois únicos espécimes de Weinmannia humilis coletados na Bahia estão estéreis e haviam sido inicialmente identificados como $W$. paulliniifolia (Amorim et al. 2009). No entanto, o espécime Amorim 5789 depositado no HUEFS foi identificado por F. Santos-Silva em 2018 (in shed.) como W. humilis. Concordamos com essa identificação porque os dois espécimes apresentam ramos maduros tomentosos e folhas com 12 a 19 folíolos. Os caracteres vegetativos em Lopes 531, no entanto, são consideravelmente menores do que em Amorim 5789, tratando-se possivelmente de um indivíduo mais jovem. Todas as medidas entre parênteses na descrição das folhas pertencem ao espécime Lopes 531. Essa variação também é percebida nos espécimes do Rio Grande do Sul (ver http://www.ufrgs.br/fitoecologia/florars/index. php). Todas as medidas das porções vegetativas são baseadas exclusivamente nos espécimes da Bahia. Ilustração em Engler (1871: pl. 40).

\subsection{Weinmannia paulliniifolia Pohl ex Ser. in A. P. de Candolle, Prodr. 4: 11. 1830.}

Figuras 4H-L, 5 e 6.

Arbustos ou arvoretas até $4 \mathrm{~m}$ alt.; ramos jovens tomentosos, glabrescentes quando maduros. Estípulas (3-)6-8 mm compr., circulares a oblongas. Folhas 5,5-10 cm compr., opostas, imparipinadas, pecíolo 0,7-1 cm compr., pecíolos e raques alados, com tricomas esparsos, segmentos interfoliolares da raque alados, alas rômbicas, vilosas entre as alas; folíolos 59, subsésseis, subcoriáceos, elípticos, lanceolados ou obovados, ápice arredondado, agudo no folíolo terminal, base atenuada, margens completamente serreadas ou apenas nos 2/3 distais, revolutas, faces adaxial e abaxial glabras, nervura central com tricomas esparsos, folíolo terminal 3-5,5 $\times 0,8-1,7 \mathrm{~cm}$, folíolos 


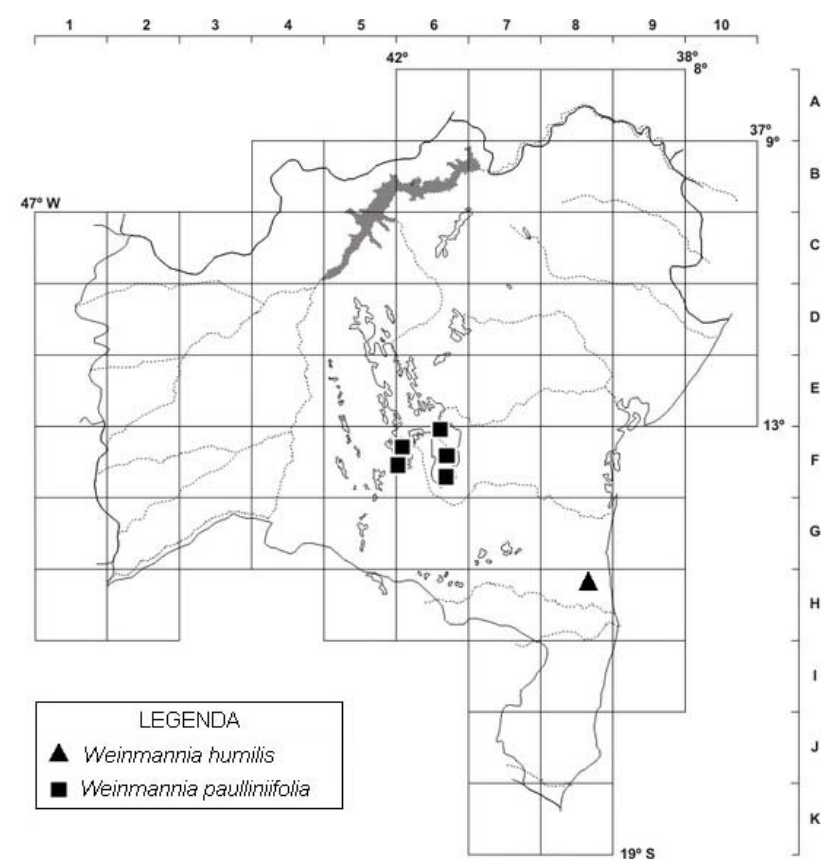

Figura 6. Distribuição de Weinmannia humilis e W. paulliniifolia no estado da Bahia.

laterais $1-4 \times 0,7-1,5 \mathrm{~cm}$. Inflorescências $5-12 \mathrm{~cm}$ compr., terminais, 2 por ápice de ramo; pedúnculo 1,5$2,5 \mathrm{~cm}$ compr., hirsuto; pedicelos $2-3 \mathrm{~mm}$ compr., pilosos. Sépalas 5 , ca. $1 \mathrm{~mm}$ compr., ovais, agudas, pubérulas; pétalas 5 , ca. 1,5 × 1,2 $\mathrm{mm}$, brancas, ovais, ápice obtuso, base truncada, côncavas, glabras, precocemente caducas; estames 10, 2,5-3 mm compr., filetes glabros; ovário $1,5-2 \times$ ca. $1 \mathrm{~mm}$, oblongo a ovoide, glabro, estiletes 1,3-2 mm compr. Cápsulas 3$6 \times 1,8-4 \mathrm{~mm}$, ovoides a oblongas. Sementes $0,8-1 \times$ $0,5-1 \mathrm{~mm}$, reniformes, com tricomas esparsos.

Weinmannia paulliniifolia ocorre em todos os estados da Região Sul, além de São Paulo, Minas Gerais e Bahia (Santos-Silva et al. 2019). F5, F6: floresta semidecídua e campo rupestre da Chapada Diamantina. Floresce entre março e setembro e frutifica de maio a janeiro.

Material selecionado - Abaíra, Catolés, Serra do Barbado, $13^{\circ} 17^{\prime} \mathrm{S}, 4^{\circ}{ }^{\circ} 54^{\prime} \mathrm{W}, 14$ out. 2006 (bot., fl.), A.K.A. Santos et al. 898 (HUEFS); Barra da Estiva, Morro do Ouro, $13^{\circ} 42^{\prime} \mathrm{S}, 41^{\circ} 18^{\prime} \mathrm{W}, 19$ nov. 1988 (fl.), R.M. Harley et al. 26951 (CEPEC, SPF); Mucugê,

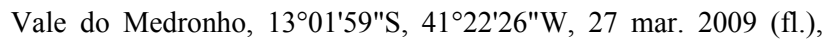
R.M. Harley \& E.R. Junior 55895 (HUEFS); Piatã, encosta da Serra do Barbado, $13^{\circ} 17^{\prime} \mathrm{S}, 41^{\circ} 54^{\prime} \mathrm{W}, 6$ set. 1996 (bot.), R.M. Harley et al. 28329 (HUEFS); Rio de Contas, Pico das Almas, 1332'S,

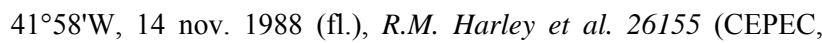
HUEFS).

Engler (1871) descreveu as folhas de Weinmannia paulliniifolia com 4- a 9-jugas (i.e., com 8 a 18 folíolos laterais), como nos espécimes do sul do país. Os espécimes da Bahia apresentam folhas 1- ou 2-jugas (i.e., com 4 a 8 folíolos laterais), assim como os espécimes descritos por Santos-Silva et al. (2017) para o Parque Estadual de Ibitipoca, em Minas Gerais. Dessa maneira, é possível que mais de uma espécie estejam sendo identificadas sob $W$. paulliniifolia e, mesmo na Flora Brasiliensis (Engler 1871), essa espécie foi classificada em duas seções. Ilustração recente em Santos-Silva et al. (2017: 110).

\section{Agradecimentos}

Os autores agradecem aos curadores dos herbários consultados; a Raymond Harley, pelas fotografias de Lamanonia speciosa e Weinmannia paulliniifolia; a Karena Pimenta, pelas ilustrações; à Fapesb, pelo auxílio financeiro ao Projeto Flora da Bahia (APR0162/2007); e ao CNPq, pelo apoio ao PROTAX (562278/2010-9) e ao projeto Flora da Bahia (483909/2012-2). Ao CNPq, também, pelas bolsas de Produtividade em Pesquisa concedidas a AMG (PQ Senior) e LPQ (PQ1-A), e de apoio técnico a LCM (372185/2019-3).

\section{REFERÊNCIAS}

Amorim, A.M.; Jardim, J.G.; Lopes, M.M.M.; Fiaschi, P.;Borges, R.A.X.; Perdiz, R.O. \& Thomas, W.W. 2009. Angiospermas em remanescentes de floresta montana no sul da Bahia, Brasil. Biota Neotropica 9: 313-348.

APG IV. 2016. An update of the Angiosperm Phylogeny Group classification for the orders and families of flowering plants: APG IV. Botanical Journal of the Linnean Society 181: 1-20.

Bernardi, A.L. 1961. Revision of Weinmannia sect. Weinmannia. Candollea 17: 123-189.

Bradford, J.C. 1998. A cladistic analysis of species-groups in Weinmannia (Cunoniaceae) based on morphology and inflorescence architecture. Annals of the Missouri Botanical Garden 85: 565-593.

Bradford, J.C. \& Barnes, R.W. 2001. Phylogenetics and classification of Cunoniaceae (Oxalidales) using chloroplast DNA sequences and morphology. Systematic Botany 26: 354-385.

Bradford, J.C.; Hopkins, H.C.F. \& Barnes, R.W. 2004. Cunoniaceae. In: K. Kubitzki (ed), The Families and Genera of Vascular Plants. Flowering plants. Dicotyledons. Celastrales, Oxalidales, Rosales, Cornales, Ericales. Vol. 6. Springer, Berlin, p. 91-111.

Costa, G.M.; São-Mateus, W.M.B.; Oliveira, R.P. \& Giulietti, A.M. 2010. Flora da Bahia: Bonnetiaceae. Sitientibus série Ciências Biológicas 10: 77-79.

Engler, H.G.A. 1871. Cunoniaceae. In: C.F.P. Martius \& A.W. Eichler (eds), Flora Brasiliensis. Vol. 14. Frid. Fleischer, Leipzig, p. 151-172.

Fuentes, A.F. \& Rogers, Z.S. 2007. Dos especies nuevas de Weinmannia (Cunoniaceae) de los bosques montanos en La Paz, Bolivia. Novon 17: 326-331.

Gutiérrez, E. 1993. Cunoniaceae. In: T. Killeen, E. García \& S. Beck (eds), Guía de Árboles de Bolivia. Herbario Nacional de Bolivia, La Paz. Missouri Botanical Garden, St. Louis, p. 245-250.

Hopkins, H.C.F. 2018. Names and types relating to the South American genus Lamanonia (Cunoniaceae) and its synonyms, the identity of $L$. speciosa, and an account of the little-known L. ulei. Kew Bulletin 73: 10. 
Marinho, L.C.; São-Mateus, W.M.B.; Costa, G.M. \& Amorim, A.M. 2015. Flora da Bahia: Theaceae. Sitientibus série Ciências Biológicas 15: 1-5.

Pirani, J.R. \& Castro, N.M. 2011. Flora da Serra do Cipó, Minas Gerais: Cunoniaceae. Boletim de Botânica da Universidade de São Paulo 29: 41-45.

Poole, I.; Cantrill, D.J.; Hayes, P. \& Francis, J. 2000. The fossil record of Cunoniaceae: new evidence from Late Cretaceous wood of Antarctica? Review of Paleobotany and Palynology 111: 127-44.

Santos-Silva, F.; Cardoso, P.H. \& Cabral, A. 2017. Cunoniaceae no Parque Estadual do Ibitipoca, Minas Gerais, Brasil. Boletim de Botânica da Universidade de São Paulo 35: 105-112.
Santos-Silva, F.; Cabral, A. \& Cardoso, P.H. 2019. Cunoniaceae. In: Flora do Brasil 2020 (em construção). Jardim Botânico do Rio de Janeiro. Disponível em: http://reflora.jbrj.gov.br/ reflora/floradobrasil/FB7125; acesso em: 6 jul. 2019.

Stevens, P.F. 2011. Angiosperm Phylogeny Website. Version 14, July 2017 [and more or less continuously updated since]. Disponível em: http://www.mobot.org/MOBOT/research/ APweb/; acesso em: 6 jul. 2019.

Zappi, D.C. \& Taylor, N.P. 1995. Cunoniaceae. In: B. Stannard (ed.), Flora do Pico das Almas. Royal Botanic Gardens, Kew, p. 287-288.

Zickel, C.S. \& Leitão-Filho, H.F.L. 1993. Revisão taxonômica de Lamanonia Vell. (Cunoniaceae). Revista Brasileira de Botânica 16: 73-91.

\section{LISTA DE EXSICATAS}

Amorim, A.M. 4830 (1.2), 5789 (2.1), 6963 (1.2), 8106 (2.2); Barbosa, E. 953 (2.1); Cardoso, D. 2400 (1.2); Conceição, A.S. 463 (2.2); França, F. 999 (1.2), 1003 (2.2); Ganev, W. 261 (1.2), 380 (2.2), 1213 (2.2); Giulietti, A.M. 1560 (1.2), s.n. SPF 18429 (2.2); Guedes, M.L. 11475 (1.2), 12276 (2.2), 12450, 17773 (1.2), 23317 (2.2), PCD 1486 (1.2); Harley, R.M. 20862, 25788, 26155, 26376, 26951, 27773 (2.2), 28312 (1.2), 28329 (2.2), 58287 (1.2); Hurbath, F. 129 (2.2); Jardim, J.G. 406, 1222, 1311, 4406 (1.2), 4911 (2.2); Juchum, F.S. 95 (2.2); Lopes, M.M.M. 531 (2.1), 832, 1551 (1.2); Matos, F.B. 1928 (1.2); Mayo, S. CFSC 7031 (1.1); Miranda, E.B. 288 (2.2); Monteiro, M.T. 23663, 23665 (1.2); Nascimento, F.H.F. 23 (2.2), 113 (1.2), 252 (2.2), 268 (1.2), 277 (2.2), 527, 1195 (1.2); Oliveira, R.B. 12 (1.2); Oliveira, R.P. 2094 (2.2); Paixão, J.L. 448 (1.2); Perdiz, R.O. 429 (1.2); Queiroz, L.P. 3236 (1.2), 5022 (2.2), 6371, 9270, 9918, 12092 (1.2); Santos, A.K.A. 898 (2.2); Santos, M.M. 157 (1.1); Santos, T.S. 2583 (1.1); Sohn, S. 36 (2.1); Souza, E.B. 995 (2.2); Torrend, C. s.n. ALCB 036750, id. ALCB 036751 (1.1); Valadão, R.M. 135 (1.2). 